\title{
Facile synthesis and catalytic properties of silver colloidal nanoparticles stabilized by SDBS
}

\author{
WEN WANG, YINMIN SONG, QUANSHENG LIU and KELI YANG* \\ College of Chemical Engineering, Inner Mongolia University of Technology, Huhhot 010051, \\ P.R. China
}

MS received 9 September 2013; revised 1 November 2013

\begin{abstract}
A facile method was explored to prepare stable silver colloidal nanoparticles (AgCNPs) in water. Sodium dodecyl benzene sulfonate (SDBS) was used as the stabilizing agent, without addition of any co-surfactant. The reaction was rapid and the product prepared at different conditions was measured by transmission electron microscopy (TEM) and UV-Vis spectroscopy. The results showed that AgCNPs stabilized by SDBS was stable in water with narrow size distribution (1-5 $\mathrm{nm}$ ). The amount of surfactant has great influence on the products. When the molar ratio of $\mathrm{Ag}^{+}$to SDBS increased to $1: 4$, AgCNPs can be obtained with high dispersion (2-3 nm), which has high catalytic activity on reduction of 4-nitrobenzoic acid to 4-aminobenzoic acid.
\end{abstract}

Keywords. Silver colloidal nanoparticles; SDBS; catalytic reduction; 4-nitrobenzoic acid.

\section{Introduction}

Silver colloidal nanoparticles (AgCNPs) have been studied extensively in catalysis, ceramics, electronics, optical and lubricants, owing to their particular physical, chemical and mechanical properties (Nawa et al 2003; Li et al 2012). While the synthesis of AgCNPs is a complex process and hence, there is a wide range of techniques available for producing different kinds of AgCNPs (Jin et al 2003; Huang and Shieu 2005; Singh S et al 2009). Chemical reduction in liquid phase is one of the most studied methods to obtain AgCNPs, which usually involves the use of capping agents to control size, shape, stability and solubility of silver nanostructures (Wani et al 2011). Organic thiol compounds, long-chain amines and surfactants are commonly used as capping agents to stabilize colloidal silver (Wani et al 2013). Sodium oleate, valine, xanthate and cyclodextrin have also been used to stabilize silver nanostructures. In addition, polymers, such as polyvinyl pyrrolidone (PVP) and polystyrene (PS) had been demonstrated as good capping agents (Huang and Shieu 2005; Junga et al 2011). These agents could cap on the surface of nanoparticles to prohibit agglomeration and sedimentation of synthesized nanoparticles (Soukupova et al 2008; Mo et al 2011).

It is worth noting that most of the processes regarding the preparation of AgCNPs in solution-phase need at least two kinds of capping agents to stabilize the particles and tailor the crystal shapes. And the severe reaction

*Author for correspondence (yangkeli@imut.edu.cn) conditions such as $\mathrm{N}_{2}$ protection are often necessary. Cheong's group (Junga et al 2011) reported the formation of silver nanoparticles using PVP and poly(4-styrenesulfonic acid-co-maleic acid) sodium salt (PPMA) as the stabilization agents. The procedure is relatively complex and the reaction time is as long as $12 \mathrm{~h}$.

The development of a facile synthesis of AgCNPs with desired shapes, sizes and uniform distributions remains a great challenge. This challenge can be made more meaningful by employing simpler and easier synthetic routes (Jana et al 2001; Sun et al 2003; Andersson et al 2005; Zhao and Nan 2012).

Sodium dodecyl benzyl sulfonate (SDBS) is an anionic surfactant, which has been widely used during the synthesis of nanomaterials by mixing with other cosurfactants such as PVP, CTAB, PVA and fructose. For example, Zhang and co-workers (2006) used SDBS as a capping agent and CTAB as a template to induce the formation of Ag nanofibre (Zhao and Nan 2012).

In our research, we report an equally facile method for the preparation of AgCNPs using SDBS as the only agent, without addition of any co-surfactant. The product of AgCNPs was stable with narrow size distribution. Catalytic reduction of 4-nitrobenzoic acid was employed as the probe reaction to test activity of the obtained silver colloid. The reason is that there are evidences of carcinogenic activity and hematological toxicity of the 4-nitrobenzoic acid in rats and mice. The reduction product (4-aminobenzoic acid) is non-toxic and does not show any carcinogenic activity (US Department of Health and Human Services 1994). 


\section{Experimental}

\subsection{Materials}

Silver acetate (AgAc, CP), SDBS $\left(\mathrm{C}_{18} \mathrm{H}_{29} \mathrm{NaO}_{3} \mathrm{~S}, \mathrm{AR}\right)$, sodium borohydride $\left(\mathrm{NaBH}_{4}, \mathrm{AR}\right)$ and ammonia solution $\left(\mathrm{NH}_{3} \cdot \mathrm{H}_{2} \mathrm{O}, 25 \%\right.$, AR) were used. All above chemicals were purchased from Shanghai Chinese Medicine Company and used as received without further purification. 4-Nitrobenzoic acid $\left(\mathrm{C}_{7} \mathrm{H}_{5} \mathrm{NO}_{4}\right.$, AR) was obtained from Sigma-Aldrich Company. Deionized water was used in all experiments.

\subsection{Characterization}

UV-Vis absorption spectra were performed with Shimadzu UV-Vis-NIR scanning spectrophotometer (UV3150) to confirm AgCNPs formation by showing the plasmon resonance.

The morphologies of the Ag nanoparticles, which were deposited on carbon-coated $\mathrm{Cu}$ grids, were evaluated using high resolution transmission electron microscopy (HRTEM, JEM-2010) at $200 \mathrm{kV}$.

\subsection{Preparation of AgCNPs}

In a normal synthesis, $5 \mathrm{~mL}$ of silver acetate $\left(1.6 \times 10^{-2}\right.$ $\mathrm{mol} / \mathrm{L})$ solution and $5 \mathrm{~mL}$ of $\operatorname{SDBS}\left(3.2 \times 10^{-2} \mathrm{~mol} / \mathrm{L}\right)$ were mixed in the conical flask at $50{ }^{\circ} \mathrm{C}$. The mixture was stirred for a period of time $(\mathrm{pH}=5-6)$. Then, $\mathrm{NaBH}_{4}$ $\left(0.4 \times 10^{-2} \mathrm{~mol} / \mathrm{L}\right)$ was dropped into the conical flask. At the initial stage of the reaction, colour of the solution was immediately changed into light yellow by the addition of $\mathrm{NaBH}_{4}$. As the reaction proceeded, the solution colour changed into light orange-brown, which confirmed the formation of silver colloidal nanoparticles.

To check the effects of various parameters, we have performed several experiments with varying the amounts of SDBS and the reaction temperatures, respectively while other reaction parameters were kept con stant.

\subsection{Catalytic activity test}

In a typical process, 4-nitrobenzoic acid (0.05 mmol) was dissolved in water and $20 \mathrm{~mL}$ of $\mathrm{NaBH}_{4}$ solution $(0.004$ $\mathrm{mol} / \mathrm{L}, 0.08 \mathrm{mmol})$ was added. Then $0.5 \mathrm{~mL}$ of silver solution $(0.016 \mathrm{~mol} / \mathrm{L}, 0.008 \mathrm{mmol})$ was added to the reaction mixture at room temperature and allowed to stir for $10 \mathrm{~min}$. The product was detected by UV-Vis spectroscopy. The amount of catalyst was changed from 0.5 to $4 \mathrm{~mL}$ to test the effect of Ag colloids on the reductive reaction.

\section{Results and discussion}

\subsection{Synthesis of AgCNPs using SDBS as capping agent}

UV-Vis spectroscopy is a widely used technique for structural characterization of the silver nanoparticles (Wani et al 2010). Figure 1 shows UV-Vis absorption spectra of synthesized AgCNPs using SDBS as the only protective agent. Absorption maxima at $408 \mathrm{~nm}$ and the light orange-brown are manifests of surface plasmon resonance (SPR), a characteristic feature of AgCNPs.

Increase in absorbance with respect to reaction time can be noticed. The highest absorption peak indicates that nano-silver particles achieved the maximum amount $(\mathrm{Wu}$ and Chen 2004). Then, absorbance of the sample did not change anymore after 30 min later. We can conclude that the reduction was completed within $30 \mathrm{~min}$. The presence of Ag particles was further confirmed by XRD measurement as shown in figure 2. XRD pattern of

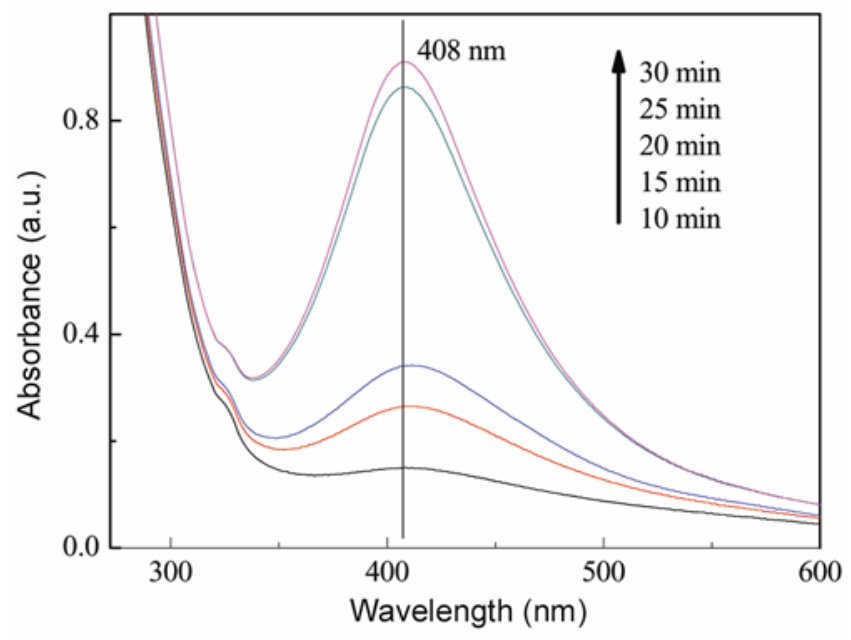

Figure 1. UV-Vis spectra of AgCNPs tested under different reaction times.

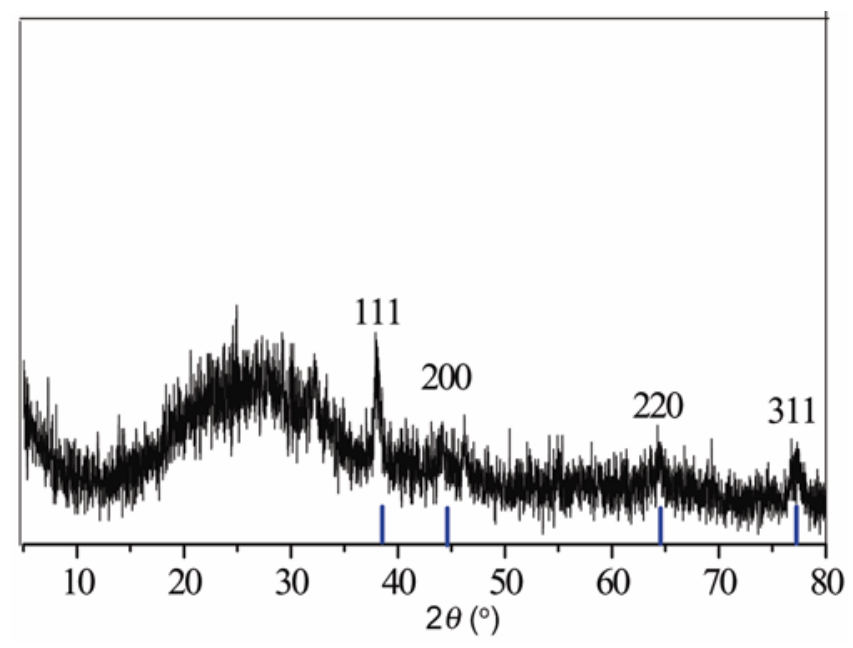

Figure 2. XRD pattern of AgCNPs capped by SDBS. 


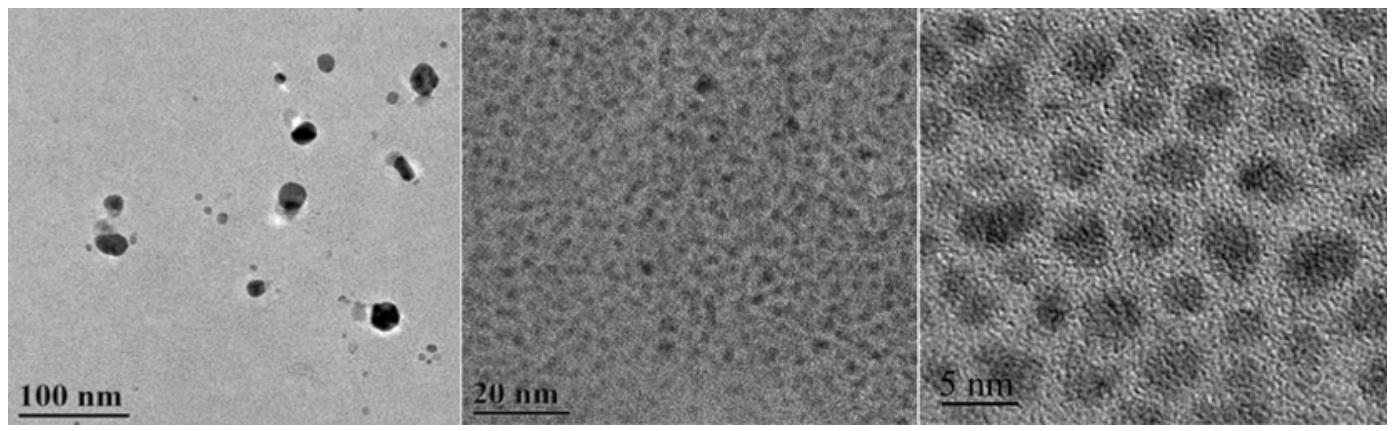

Figure 3. HRTEM images of AgCNPs prepared at normal conditions.

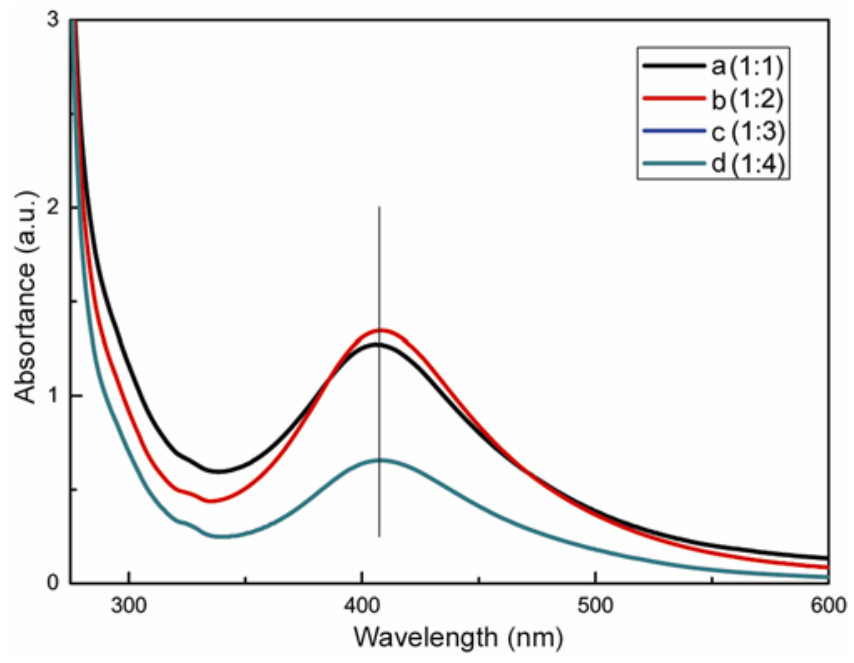

Figure 4. UV-Vis absorption spectra of AgCNPs synthesized with different molar ratios of AgAc to SDBS.

Ag particles revealed a number of relatively inconspicuous peaks, indicating that a little crystalline was present. According to the Joint Committee for Powder Diffraction Studies (JCPDS) card (no. 04-0783), it was clear that the peaks may be assigned to the diffractions of the (111), (200), (220) and (311) planes of cubic Ag. The broad peak $\left(20-30^{\circ}\right)$ related to the existence of SDBS.

TEM image of the AgCNPs solution also showed formation of scattered and spherical silver particles with size in the range of $<6 \mathrm{~nm}$ (figure 3 ). Little aggregation among the formed particles took place and relatively bigger nanoparticles were observed. This result was identical to that of figure 2 .

\subsection{Effect of amount of SDBS}

SDBS was used as the only capping agent to induce AgCNPs formation in our research. The amount of SDBS was an important factor affecting the silver nanoparticles synthesis.

Figure 4 shows UV-Vis spectra of aqueous nano-silver colloid synthesized with different molar ratios of AgAc to
SDBS. The absorption bands are centred at about $407 \mathrm{~nm}$ (Chen and Gao 2007; Popa et al 2007). This observed peak position (curves B and C are overlapped) confirmed the formation of nano-sized silver particles (Kleemann 1993). There was almost no shift in the peak position. The good symmetric absorption peaks with an early unchanged width implied that size of the nanoparticles was very uniform.

Usually, whether the formation of nano-sized silver particles with narrow size distribution is accomplished or not can be predicted by analysis of UV absorption peak (Huang and Shieu 2005). If the absorption peak is narrower, the particle size is smaller and the distribution is better. However, if the diameter of silver particles is less than or equal to $3 \mathrm{~nm}$, the peak width and the maximum absorption of the plasmon peak will strongly depend on the surrounding medium (Charle et al 1984). To further determinate size and distribution of AgCNPs, TEM was performed as seen in figure 5 .

TEM images of AgCNPs synthesized with different amounts of SDBS are shown in figure 5, indicating that the morphology of AgCNPs obtained at $\mathrm{Ag}^{+}$:SDBS molar ratio of $1: 1$ were irregular and some relatively large particles were formed, likely arising from particle aggregation. With increasing amount of SDBS, the particle size of the AgCNPs became small and the particles were uniform with high dispersion. It can be found from the size distribution histograms of AgCNPs obtained at molar ratio of $1: 1$ (figure $6 a$ ), that average size of silver nanoparticles was about $6 \mathrm{~nm}$ (range 5-10 nm). On increasing the molar ratio to $1: 2$ (figure $6 \mathrm{~b}$ ), the average size of AgCNPs obtained was down to about $3 \mathrm{~nm}$ (range 1-5 nm). Further, increase in molar ratio to $1: 4$ (figure 6d) resulted in a slight decrease in the average particle size of $2.7 \mathrm{~nm}$ (range $1-4 \mathrm{~nm}$ ). This colloid was observed to be very stable in the solution even one month after its synthesis, which validated the application of single SDBS as capping agent for the synthesis of AgCNPs.

As we know, SDBS molecule is composed of hydrophilic ion-head and hydrophobic carbon chain. When the concentration of SDBS is high, assembly of hydrophobic groups often results in the formation of micelles. 

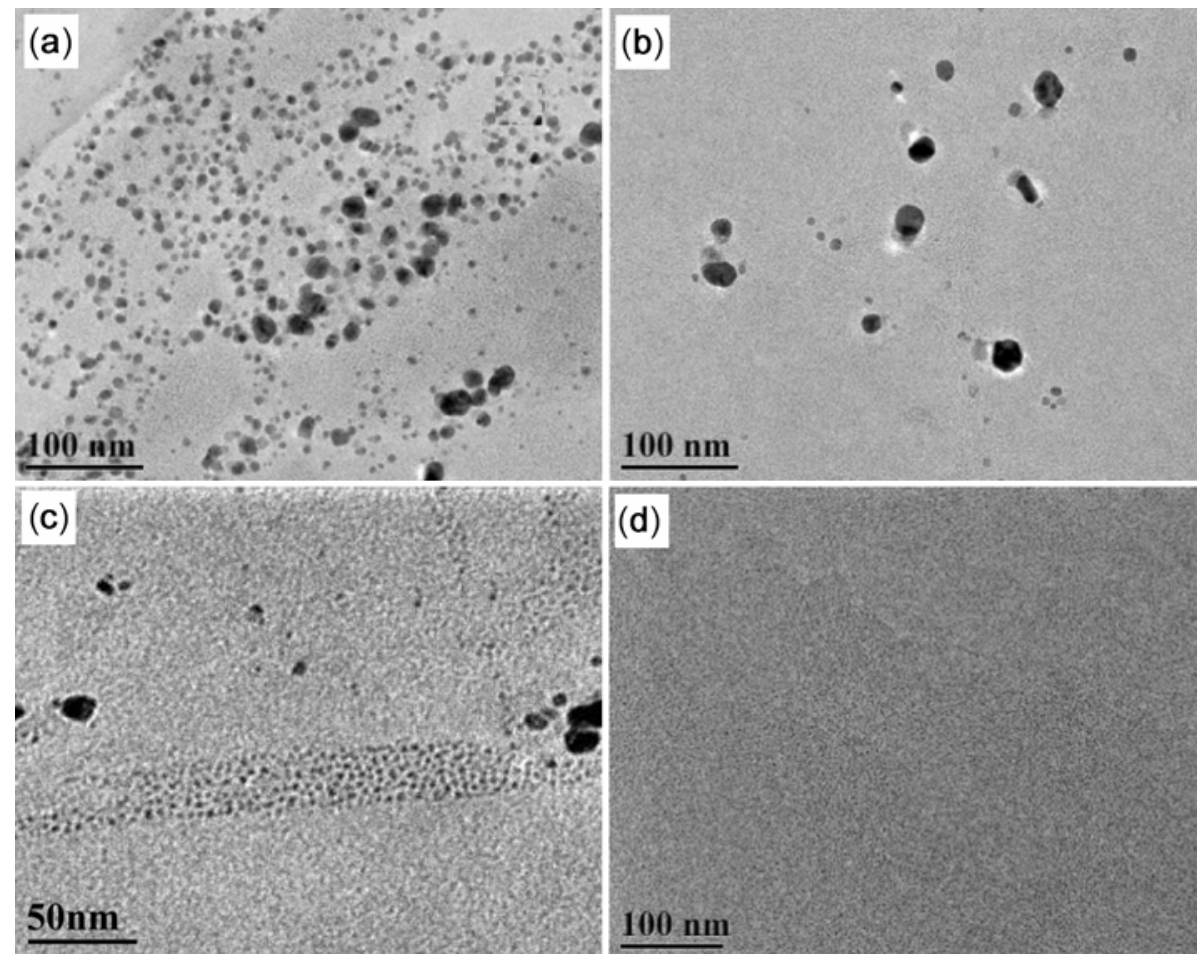

Figure 5. HRTEM images of AgCNPs synthesized with different $\mathrm{Ag}^{+}$:SDBS molar ratios (a) $1: 1$, (b) $1: 2$, (c) $1: 3$ and (d) $1: 4$.
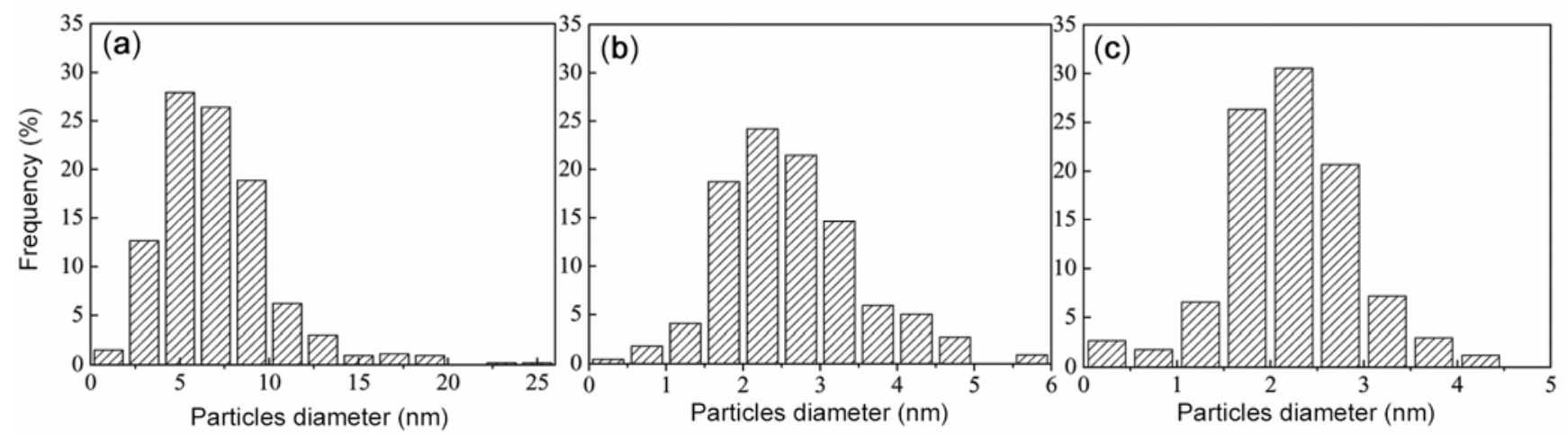

Figure 6. Particle size analysis of AgCNPs synthesized with different $\mathrm{Ag}^{+}:$SDBS molar ratios (a) $1: 1$, (b) $1: 2$ and (c) $1: 4$.

The hydrophilic ion-head of SDBS will be in the aqueous phase. In our research, concentration of SDBS was much higher than that of critical micellar concentration $\left(\mathrm{CMC}=1.6 \times 10^{-3} \mathrm{~mol} / \mathrm{L}\right)$. According to the morphology of AgCNPs, we considered that monolayer micelle model could be used to describe the Ag crystal formation mechanism (US Department of Health and Human Services 1994). First, high concentration of SDBS assembled into the spherical micelles, which had strong interaction with $\mathrm{Ag}^{+}$. SDBS played two roles in the process: as a capping agent to form AgCNPs and a dispersant of AgCNPs to obtain mono-dispersed spherical AgCNPs with small size as described in figure 7 . Then, the strong electrostatic repulsion of micelles could keep the nanoparticles dispersion stable for a longer time.

The oxidative corrosion and aggregation of Ag nanoparticles can be effectively eliminated with high concentration of this protective agent, probably allowing stable nanoparticle solutions to exist over a wide range of $\mathrm{pH}$.

\subsection{Effect of $p H$}

Effect of $\mathrm{pH}$ on the size distribution of nanoparticles has been reported widely (Doty et al 2005). Chen and co-workers (2010) demonstrated that the size of 


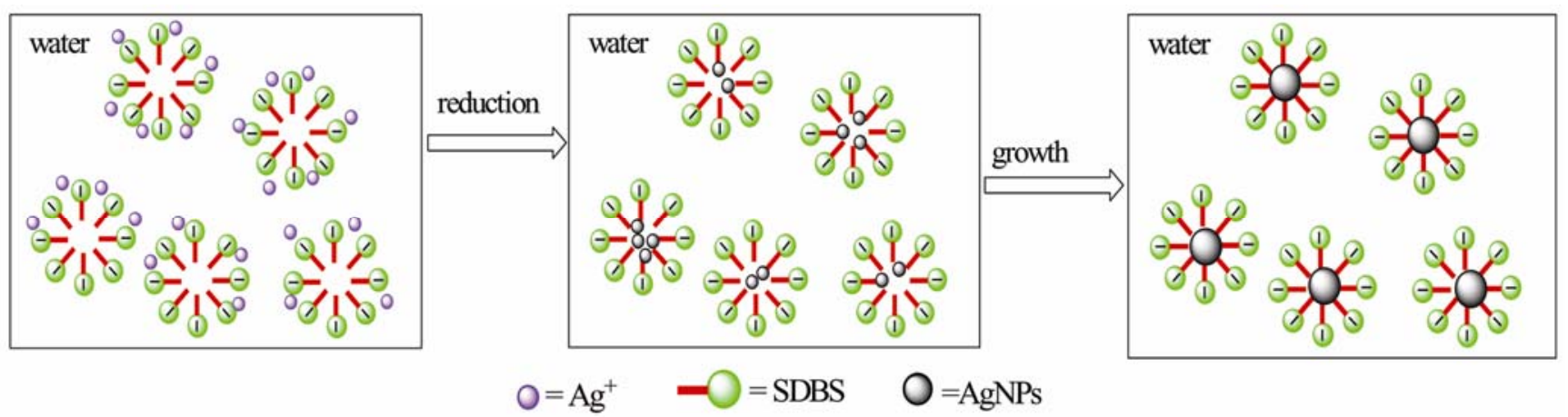

Figure 7. Schematic formation mechanism for SDBS protected AgCNPs.

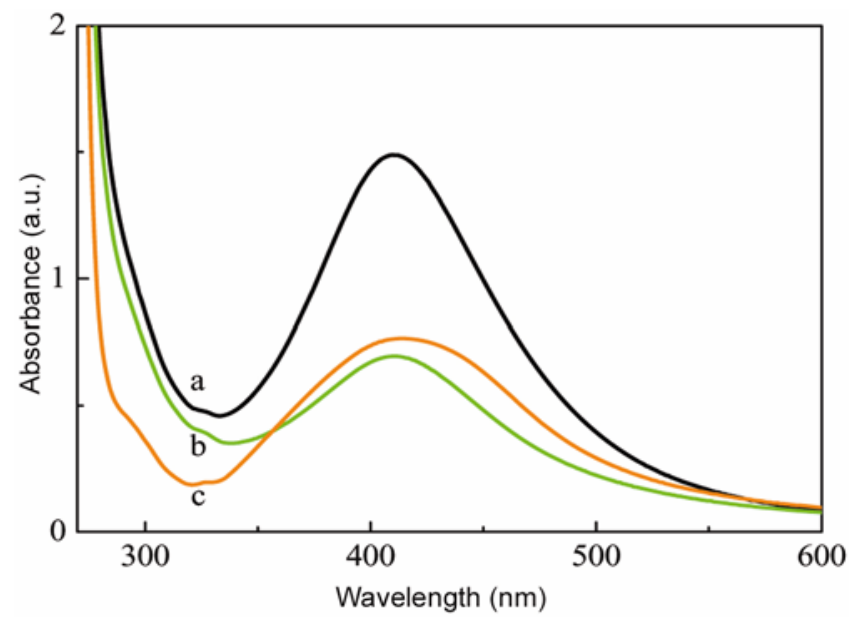

Figure 8. UV-Vis spectra of AgCNPs prepared at (a) $\mathrm{pH}=7$, (b) $\mathrm{pH}=9$ and (c) $\mathrm{pH}=10$.

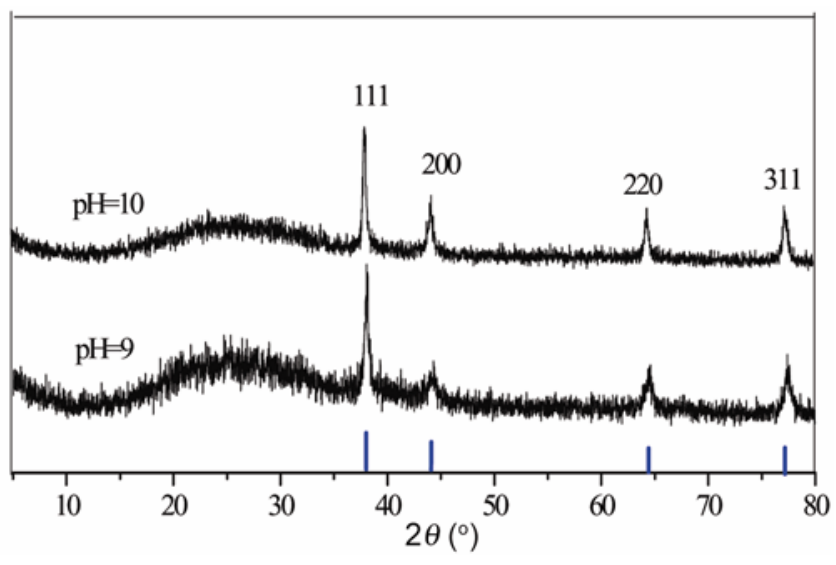

Figure 9. XRD patterns of AgCNPs prepared at $\mathrm{pH}=9$ and 10.

AgCNPs particles changed over a certain $\mathrm{pH}$ range depending on the amount of $\mathrm{NaOH}$ added to the reaction system (AgCl colloids + PVP + ascorbic acid solution). When the dosage of $\mathrm{NaOH}$ was reduced, size of the as-prepared Ag particles became larger. Fabrega et al (2009) reported that size of the Ag cluster did not vary significantly with $\mathrm{pH}$ value, when AgCNPs are suspended in minimal Davies Medium. To determine AgCNPs size with respect to $\mathrm{pH}$, the surroundings of reaction system must be considered.

SDBS is an acidic surfactant. Size of above-mentioned AgCNPs were recorded under acidic conditions $(\mathrm{pH}=5-$ 6 ), so the solution of silver colloid was adjusted to $\mathrm{pH}=7-10$ by the addition of liquid ammonia to avoid formation of AgOH. Figure 8 shows UV-Vis spectra of silver colloids capped by SDBS at different $\mathrm{pH}$ conditions.

The broad peaks were observed at $408 \mathrm{~nm}$ (curves a, b) and $413 \mathrm{~nm}$ (curve c). Absorption band shift of AgCNPs upon aggregation or assembly had been reported, which was related to the change of particle shape and size and red-shift of the band indicated the cluster growth and large particle size (Zhang et al 2006).

XRD patterns of the above-mentioned particles were recorded in figure 9 and the crystalline phase of pure silver powder rather than any other phase such as $\mathrm{AgOH}$ were detected. XRD patterns of samples displayed distinct diffraction peaks $(2 \theta)$ at $38.2^{\circ}(111), 44 \cdot 6^{\circ}$ (200), $64.8^{\circ}(220)$ and $77.9^{\circ}$ (311), respectively which corresponded to the typical cubic Ag particles. The sharp peaks further confirmed growth of nano-silver particles in the higher $\mathrm{pH}$ systems.

Figure 10 shows TEM images of the samples. It was obvious that with increase in $\mathrm{pH}$ value, the average particle size greatly increased. The particles were still dispersed in the form of little nanosize at $\mathrm{pH} \mathrm{7}$, the aggregation at $\mathrm{pH} 9$ and 10 were dominant. It was likely that SDBS lost their charge under basic conditions, hence, insufficient protection of the particle surface (Singh M et al 2009; Badawy et al 2010).

\subsection{Catalytic reduction of 4-nitrobenzoic acid}

Different amounts of nano-Ag colloidal catalyst $\left(\mathrm{Ag}^{+}\right.$: SDBS molar ratio $=1: 4$ ) was used in the probe reaction 

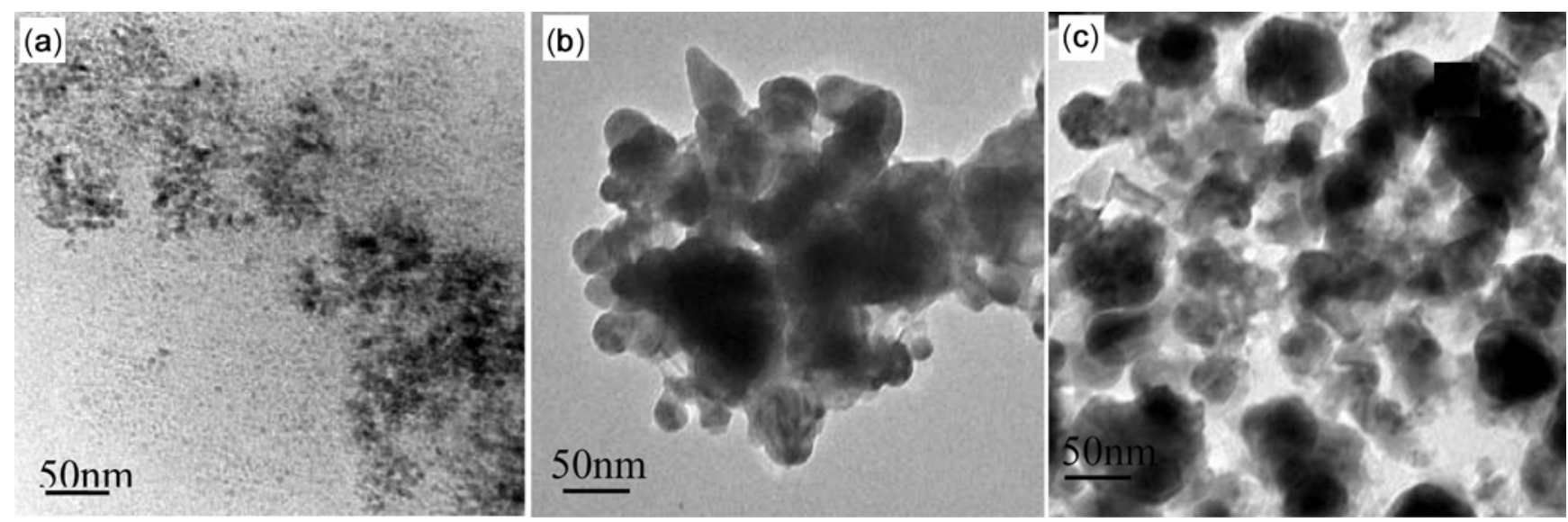

Figure 10. HRTEM images of AgCNPs stabled at (a) $\mathrm{pH}=7$, (b) $\mathrm{pH}=9$ and (c) $\mathrm{pH}=10$.

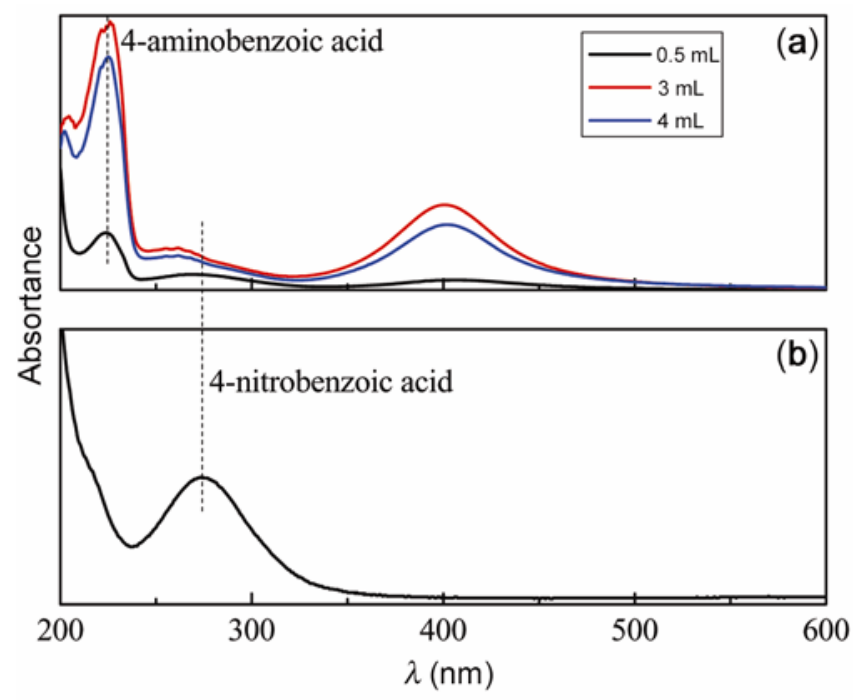

Figure 11. Reduction of 4-nitrobenzoic acid catalyzed by different amounts of AgCNPs.<smiles>Nc1ccc(C(=O)O)cc1</smiles>

Scheme 1.

(scheme 1) and the products were diluted and detected by UV-Vis spectroscopy.

Without using any catalyst, reaction cannot happen in the $\mathrm{NaBH}_{4}$ solution $(0.08 \mathrm{mmol})$ and 4-nitrobenzoic acid $(0.05 \mathrm{mmol})$ system (figure $11 \mathrm{a})$. When $0.5 \mathrm{~mL}$ of
nano-Ag colloidal (0.008 mmol) was added, the reduction happened rapidly and the absorption band of 4aminobenzoic acid appeared. With the increase in the volume of AgCNPs, the reaction was accomplished in a few minutes and most 4-nitrobenzoic acid was reduced into 4-aminobenzoic acid. As shown in figure 11(b), the absorption band of 4-aminobenzoic acid increased drastically.

$\mathrm{Rh} / \mathrm{C}$ and $\mathrm{Ru} / \mathrm{C}$ are substantially active in catalytic reduction of 4-nitrobenzoic acid, but large amounts of these catalysts are needed (Kaye and Roberts 1961). We confirmed that AgCNPs stabilized only by SDBS was very active, affording high yields of 4-aminobenzoic acid.

\section{Conclusions}

SDBS-stabilized Ag nanoparticles were prepared by reducing silver acetate using $\mathrm{NaBH}_{4}$ as the reducing agent without using any co-surfactant. The size of particles was around $3 \mathrm{~nm}$ with narrow distribution. The synthesis method presented in this paper was facile, for example, although the reaction temperature was low $\left(50^{\circ} \mathrm{C}\right)$, the reaction was fast without taking many protective measures. SDBS was found to be good capping agent in the formation of AgCNPs. Studies found that the concentration of surfactant and $\mathrm{pH}$ value had great influence on the products. Ag colloids capped only by SDBS had high activity in catalytic reduction of 4-nitrobenzoic acid to 4-aminobenzoic acid.

\section{Acknowledgements}

This work was supported by High School Scientific Research Fund of Inner Mongolia Education Department (NJZY13116) and Scientific Research Fund of Inner Mongolia University of Technology (ZS201013). 


\section{References}

Andersson M, Pedersen J S and Palmqvist A E C 2005 Langmuir 2111387

Badawy A M E et al 2010 Environ. Sci. Technol. 441260

Charle K P, Frank F, Schulze W and Bunsen-Ges B 1984 Phys. Chem. 88350

Chen B, Jiao X and Chen D 2010 Cryst. Growth \& Des. 10 3378

Chen Z and Gao L 2007 Mater. Res. Bull. 421657

Doty R C, Tshikhudo T R, Brust M and Fernig D G 2005 Chem. Mater. 174630

Fabrega J, Fawcett S R, Renshaw J C and Lead J R 2009 Environ. Sci. Technol. 437285

Huang C J and Shieu F -S 2005 Coll. Polym. Sci. 284192

Jana N R, Gearheart L and Murphy C J 2001 Adv. Mater. 13 1389

Jin R C, Cao Y C, Hao E C, Metraux G S, Schatz G C and Mirkin C A 2003 Nature 425487

Jung Y J, Govindaiah P, Choi S W, Cheong I W and Kim J H 2011 Synth. Metals 1611991

Kaye J A and Roberts J M 1961 J. Am. Chem. Soc. 7627

Kleemann W 1993 Int. J. Mod. Phys. B7 2469
Li S, Liu P and Wang Q 2012 Appl. Surf. Sci. 263613

Mo L, Liu D, Li W, Li L, Wang L and Zhou X 2011 Appl. Surf. Sci. 2575746

Nawa M, Baba R, Nakabayashi S and Dushkin C 2003 Nano Lett. 3293

Popa M et al 2007 Colloids Surf. A303 184

Singh M, Sinha I and Mandal R K 2009 Mater. Lett. 63425

Singh S, Patel P, Jaiswal S, Prabhune A A, Ramana C V and Prasad B L V 2009 New J. Chem. 33646

Soukupova J, Kvitek L, Panacek A, Nevecna T and Zboril R 2008 Mater. Chem. Phys. 11177

Sun Y, Mayers B, Herricks T and Xia Y 2003 Nano Lett. 37

US Department of Health and Human Services 1994 National Toxicology Program. Technical Report 442

Wani I A, Khatoon S, Ganguly A, Ahmed J, Ganguli A K and Ahmad T 2010 Mater. Res. Bull. 451033

Wani I A, Ganguly A, Ahmed J and Ahmad T 2011 Mater. Lett. 65520

Wani I A, Khatoon S, Ganguly A, Ahmed J and Ahmad T 2013 Coll. Surf. B101 243

Wu S H and Chen D H 2004 J. Coll. Interf. Sci. 273165

Zhang W, Qiao X and Chen J 2006 Chem. Phys. 330495

Zhao B and Nan Z 2012 Mater. Sci. Eng. C32 1971 